\title{
Copper(II) complexes with imino phenoxide ligands: synthesis, characterization, and their application as catalysts for the ring-opening polymerization of rac-lactide
}

\author{
Mrinmay Mandal ${ }^{1,2} \cdot$ Kerstin Oppelt $^{1} \cdot$ Manuela List $^{3} \cdot$ Ian Teasdale $^{4} \cdot$ \\ Debashis Chakraborty $^{5}$ - Uwe Monkowius ${ }^{1}$ (D)
}

Received: 8 June 2016/ Accepted: 26 July 2016/Published online: 5 September 2016

(c) The Author(s) 2016. This article is published with open access at Springerlink.com

\begin{abstract}
Four new copper complexes based on bidentate imino phenoxide ligands were synthesized and characterized by IR, UV-Vis spectroscopy, ESI mass spectrometry, single crystal X-ray diffraction, and electrochemistry. The crystal structures revealed that the copper(II) atoms are surrounded by phenolate oxygen and imine nitrogen atoms of two ligands in a distorted square-planar geometry. The existence of ligand-centered, as well as $\mathrm{Cu}(\mathrm{II})$-centered quasi-reversible and reversible redox reactions are observed in the cyclic voltammetry experiments of all the complexes. All complexes are able to catalyze the ringopening polymerization of rac-lactide yielding polymers with moderate molecular weights and moderately broad molecular weight distributions.
\end{abstract}

Electronic supplementary material The online version of this article (doi:10.1007/s00706-016-1830-7) contains supplementary material, which is available to authorized users.

Debashis Chakraborty

dchakraborty@iitm.ac.in

Uwe Monkowius

uwe.monkowius@jku.at

1 Institute of Inorganic Chemistry, Johannes Kepler University Linz, Altenbergerstr. 69, 4040 Linz, Austria

2 Department of Chemistry, Indian Institute of Technology Patna, Patna, Bihar 800 013, India

3 Institute for Chemical Technology of Organic Materials, Johannes Kepler University Linz, Altenbergerstr. 69, 4040 Linz, Austria

4 Institute of Polymer Chemistry, Johannes Kepler University Linz, Altenbergerstr. 69, 4040 Linz, Austria

5 Department of Chemistry, Indian Institute of Technology Madras, Chennai, Tamil Nadu 600 036, India
Graphical abstract

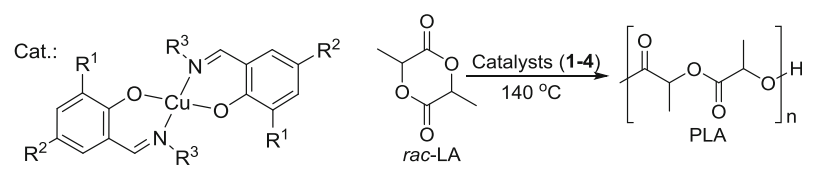

Keywords Imino phenoxide - Copper - Crystal structure · ROP $\cdot r a c$-Lactide $\cdot$ Cyclic voltammetry $\cdot$ Poly(lactic acid)

\section{Introduction}

In a similar fashion to tetradentate salen-type ligands, the related bidentate imino phenoxide ligands have proven to be extremely versatile ligands for main group, as well as transition metals. Such ligands have been used in almost all areas of coordination chemistry to prepare complexes which are catalytic and biological active or which feature interesting structural, electrochemical or magnetic properties $[1,2]$.

In recent studies, we have used imino phenoxide ligands to prepare early transition and main group metal complexes as polymerization catalysts, in particular, for the preparation of aliphatic polyesters such as poly(lactic acid) (PLA) and poly(caprolactone) (PCL) [3-8]. Such aliphatic polyesters are interesting, as one of the most important families of environmentally benign biodegradable polymers [9-14]. The degradation pathway is well studied: PLA degrades to the metabolisable lactic acid [15-17]. Generally, aliphatic polyesters are synthesized by the ringopening polymerization (ROP) of cyclic esters using metalbased initiators [18-25]. $\mathrm{Sn}(\mathrm{Oct})_{2}$ is traditionally used for the industrial production of PLA, however, it is not 
Scheme 1

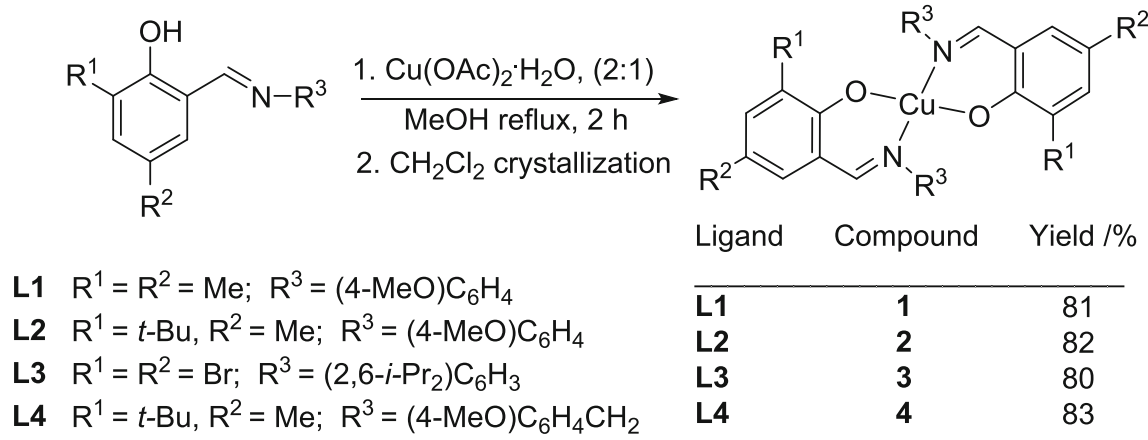

suitable for producing PLA for biomedical applications due to the toxicity of the residual metal $[13,26]$. Therefore, the syntheses of complexes with biologically benign metals are important.

$\mathrm{Cu}$ (II)-based catalysts have been widely investigated for the ROP of lactide (LA) before [27-33]. All studied catalytic systems are able to polymerize LA, however, with low activity and selectivity and at high temperatures. More recently, $\mathrm{Cu}(\mathrm{II})$ complexes bearing either the ligand set diketiminate/isopropoxide or ligands based on cyclohexane-1,2-diamine were used as catalysts for the polymerization of rac-lactide (rac-LA) [34, 35]. The catalysis of these systems was very efficient resulting in the formation of PLA in a controlled manner and displayed very high activities. Also diimino pyrrolide copper alkoxide complexes for the isotactic ROP of rac-LA gives polymers with suitably high $M_{\mathrm{n}}(44-45 \mathrm{~kg} / \mathrm{mol})$ and controlled molecular weight distributions (MWDs) (1.0-1.2) [36]. On the other hand, Wang et al. reported copper complexes bearing bis(imino) phenoxide derived ligands with reactivities which were practically either zero or the formation of only trace polymer was observed for the ROP of $\varepsilon$-caprolactone [37].

In continuation of our previous work on metal complexes containing imino phenoxide ligands, we describe herein the use of these ligands for the synthesis of four novel $\mathrm{Cu}$ (II) complexes. In principle, this class of complexes is well studied for different applications [38-55]. These complexes are easy to prepare and stable towards air and moisture and, therefore, they are much easier to handle compared to the sensitive polymerization catalysts based on 1st, 4th, 5th, and 13th group metals [3-7]. The imino phenoxide ligands used in the study were available from previous studies. Due to the fact that these $\mathrm{Cu}$ (II) complexes feature interesting structural, electronic, and spectroscopic properties, we also studied these compounds by single crystal X-ray diffraction, UV-Vis spectroscopy, and spectro-electrochemistry. Finally, their catalytic efficiency towards the polymerization of rac-LA was investigated.

\section{Results and discussion}

\section{Synthesis and characterisation}

The bidentate imino phenoxide ligands L1-L4 were prepared following a procedure reported in the literature $[56,57]$ : the complexes were synthesized by mixing a methanolic solution of the Schiff base and copper acetate $(0.5 \mathrm{mmol})$ in $10 \mathrm{~cm}^{3}$ methanol. After refluxing for $2 \mathrm{~h}$ the complexes $\mathbf{1}-\mathbf{4}$ could be isolated in high yields and purities (Scheme 1).

The purity of the complexes was confirmed by elemental analysis. Electrospray ionization mass spectra show the presence of $\mathrm{L}_{2} \mathrm{CuH}^{+} / \mathrm{L}_{2} \mathrm{CuNa}^{+}$ion peaks indicative for a 2:1 structure. The coordination of ligands to the copper(II) atom is also visible in the IR spectra (Figs. S1 and S2): the shift of $\mathrm{C}=\mathrm{N}$ stretching frequency of the ligands (1623-1632 $\left.\mathrm{cm}^{-1}\right)$ towards lower frequencies (1606-1620 $\mathrm{cm}^{-1}$ ) upon complexation confirmed the coordination of the azomethine nitrogen to the metal atom. The signals in the ${ }^{1} \mathrm{H}$ NMR spectra of all complexes are very broad due to the paramagnetic nature of the $\mathrm{Cu}$ (II) ion and hence, no further NMR analysis was performed.

\section{Structural studies}

All complexes were obtained as crystalline solids suitable for single crystal X-ray analysis by slow evaporation of dichloromethane from their solutions. Because crystals of 4 were of very low quality also the resulting crystallographic data are very poor. Therefore, these data are not discussed here but can be found in the ESI for the sake of completeness (Fig. S3 and Table S1). Detailed crystallographic data for 1-3 are presented in Table 5. The 
Fig. 1 Molecular structures of 1-3. Displacement ellipsoids were drawn at $50 \%$ probability level (exception 1: $30 \%$ ).

Hydrogen atoms are omitted for clarity

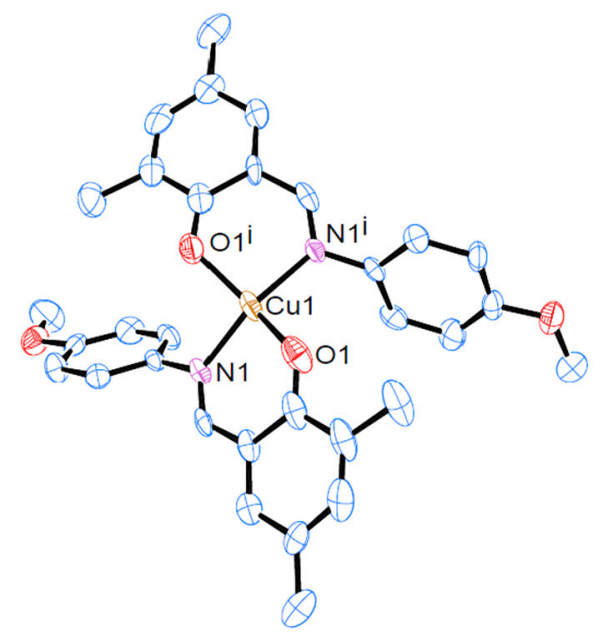

1

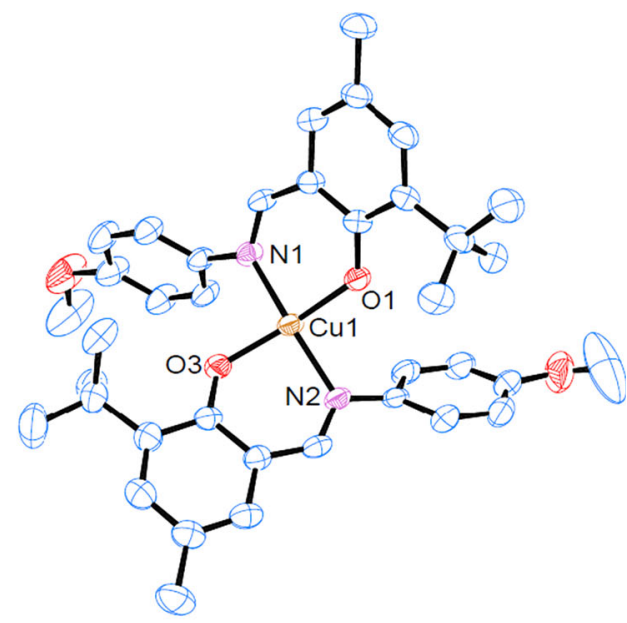

2

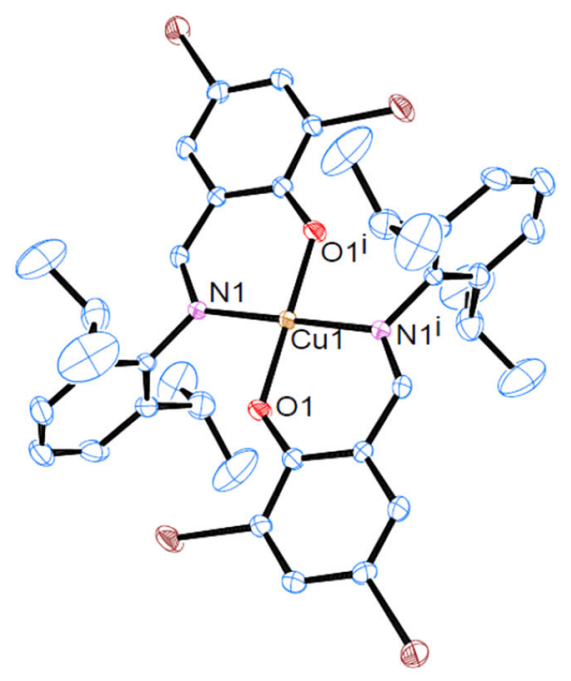

3

molecular structures of $\mathbf{1 - 3}$ are depicted in Fig. 1 and selected bond lengths and bond angles are summarized in Table 1. Complex 1 was found to crystallize in the orthorhombic space group $F d d 2$, complex $\mathbf{3}$ in the triclinic space group $P \overline{1}$. For both complexes, the asymmetric unit consist of one half of a formula unit. Complex 2 crystallizes in the monoclinic space group $C 2$ / $c$, complex 4 in $P \overline{1}$ with each containing one formula unit per asymmetric unit. In all complexes, the copper atom is coordinated by two phenolate oxygen and two imine nitrogen atoms of the ligands in a trans configuration. For $\mathbf{3}$, the copper atom exists in a perfect squareplanar coordination environment. In the other complexes the coordination geometry deviates considerably from planarity due to steric repulsion of the alkyl-substituents in ortho position of the phenoxide moiety. For $\mathbf{3}$, the bromine atom is somewhat smaller than the alkyl groups, which reduces the steric hindrance. Additional stabilization is gained by $\mathrm{C}-\mathrm{Br} / \pi$-interactions: the bromine atom points directly to the $\pi$-system of the phenyl group of the aniline moiety with a distance between the ring plane and the bromine atom of $\sim 3.38 \AA$ which is typical for such interactions [38, 39]. In the complexes, the $\mathrm{Cu}-\mathrm{O}$ bond distances are in average only slightly shorter than the $\mathrm{Cu}-$ $\mathrm{N}$ bonds $(\sim 1.92$ vs. $\sim 1.97 \AA)$. The bite angle of the ligand in $\mathbf{3}$ is considerably smaller $\left(87.95^{\circ}\right)$ than the bite angle of the other three complexes $\left(92.1^{\circ}-93.3^{\circ}\right)$. These structural parameters are very similar to reported examples of this group of complexes [38-51]. For all complexes, the crystal packing is stabilized by multiple interactions like $\mathrm{CH} / \pi, \pi / \pi, \mathrm{CH} / \mathrm{O}$, and $\mathrm{C}$ (benzylic) $/ \pi$ interaction (see crystal packing diagrams in Figs. S4-S6, ESI). The structural parameters for these weak interactions are comparable with literature values [58-61]. 
Table 1 Selected bond lengths $/ \AA$ and bond angles $/{ }^{\circ}$ for $\mathbf{1 - 3}$

\begin{tabular}{llll}
\hline & $\mathbf{1}$ & $\mathbf{2}$ & $\mathbf{3}$ \\
\hline $\mathrm{Cu}-\mathrm{O}$ & $1.921(10)$ & $1.899(3)$ & $1.896(3)$ \\
& & $1.889(3)$ & \\
$\mathrm{Cu}-\mathrm{N}$ & $1.968(9)$ & $1.982(4)$ & $1.990(3)$ \\
& & $1.972(4)$ & \\
$\mathrm{O}-\mathrm{Cu}-\mathrm{O}$ & $152.4(7)$ & $156.33(17)$ & $179.999(1)$ \\
$\mathrm{N}-\mathrm{Cu}-\mathrm{N}$ & $153.5(6)$ & $161.73(19)$ & 180.0 \\
$\mathrm{O}-\mathrm{Cu}-\mathrm{N}^{\mathrm{a}}$ & $93.1(4)$ & $92.32(16) / 92.03(15)$ & $92.05(13)$ \\
$\mathrm{O}-\mathrm{Cu}-\mathrm{N}$ & $93.1(4)$ & $91.46(15) / 91.66(16)$ & $87.95(13)$ \\
\hline
\end{tabular}

${ }^{\text {a }}$ Bite angle of the ligand

Table 2 UV-Vis spectroscopic data of the complexes 1-4

\begin{tabular}{lc}
\hline Substance & $\lambda / \mathrm{nm}\left(\varepsilon / \log \left(\mathrm{dm}^{3} \mathrm{~mol}^{-1} \mathrm{~cm}^{-1}\right)\right)$ \\
\hline $\mathbf{1}$ & $281(\mathrm{sh}, 4.40), 302(4.44), 315(\mathrm{sh}, 4.40), 381(4.10), 410$ \\
& $(4.07)$ \\
$\mathbf{2}$ & $301(4.46), 314(4.43), 413(4.15), 681$ \\
$\mathbf{3}$ & $243(4.68), 280(4.44), 306(\mathrm{sh}, 4.19), 384(4.11), 408(\mathrm{sh}$, \\
& $4.10), 661$ \\
$\mathbf{4}$ & $245(\mathrm{sh}, 4.46), 277(4.30), 328(3.80), 387(3.83), 757$ \\
\hline
\end{tabular}

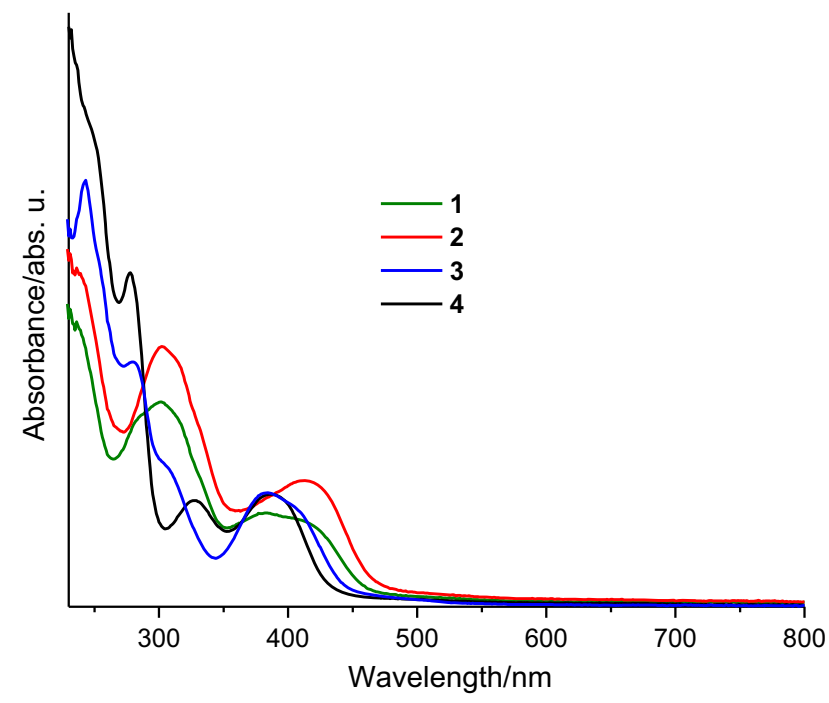

Fig. 2 UV-Vis absorption spectra of $\mathbf{1 - 4}$ in dichloromethane $\left(c \approx 10^{-5} \mathrm{~mol} \mathrm{dm}^{-3}\right)$

\section{Electronic spectra}

The electronic spectra of all complexes were recorded in $\mathrm{CH}_{2} \mathrm{Cl}_{2}$ in the range of $200-800 \mathrm{~nm}$. The data are summarized in Table 2. The bands below $350 \mathrm{~nm}$ are assigned to ligand $\pi-\pi^{*}$ transitions (Fig. 2) [62]. The broad bands between 380 and $410 \mathrm{~nm}$ are attributed to ligand-to-metal charge transfers (LMCT) [44]. For 2-4 very weak d-d

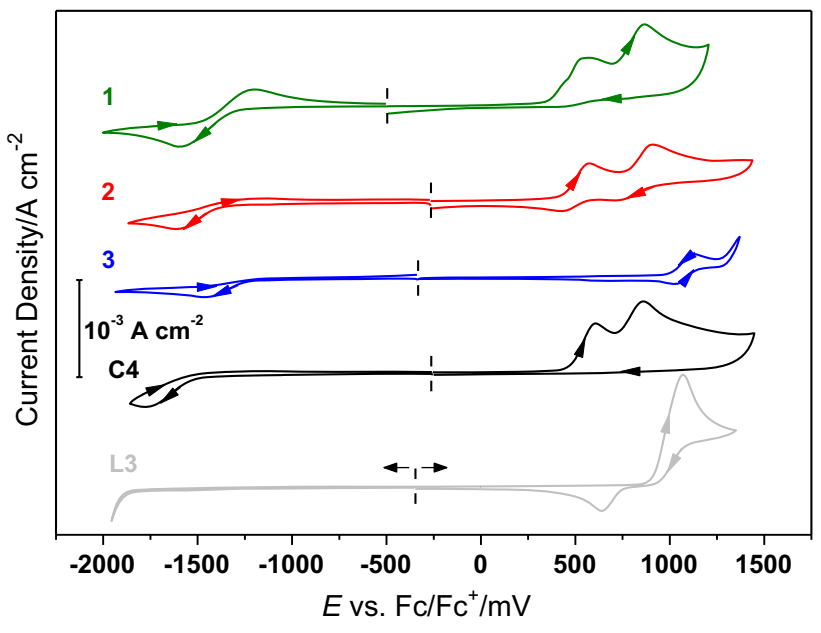

Fig. 3 Cyclic voltammograms of complexes 1-4 and ligand 3

transitions are found beyond $650 \mathrm{~nm}$ at very high concentrations (Fig. S7) [46, 53].

\section{(Spectro)electrochemistry}

The electrochemical behavior of complexes $\mathbf{1 - 4}$, as well as of ligand $\mathbf{L} \mathbf{3}$ was investigated by cyclic voltammetry (CV) in $\mathrm{CH}_{2} \mathrm{Cl}_{2}$ solutions containing $0.1 \mathrm{M}$ of $\left[\mathrm{Bu}_{4} \mathrm{~N} \mathrm{PF}_{6}\right.$ as supporting electrolyte. The ferrocene/ferrocenium $\left(\mathrm{Fc} / \mathrm{Fc}^{+}\right)$ redox pair was used as internal standard. The oxidative and the reductive scan were conducted separately due to the deposition of a brownish-red metallic material (presumably copper) on the working electrode which could be observed after cathodic scanning.

Within the electrochemical potential window of the solvent and electrolyte, all investigated complexes show a single reduction (Fig. 3). Most authors assign this first reduction potential to the reduction of the neutral $\mathrm{Cu}$ (II) imino phenoxide complex to the anionic $\mathrm{Cu}(\mathrm{I})$ complex. The stability of the reduced form varies significantly among the complexes and this is represented by large differences of the $I_{\mathrm{pa}} / I_{\mathrm{pc}}$ ratio of the reductive wave which is a measure of different reversibilities of the redox process. The redox potential for $\mathrm{Cu}(\mathrm{II})$ alkyl imino phenoxide shows differences for square-planar and non-planar coordination and has been systematically studied by polarography [52]. The authors found that the higher the deviation from the square-planar coordination the higher the reduction potential, i.e., the easier the complex is reduced. However, no such purely structural-based trends could be observed for the $\mathrm{Cu}(\mathrm{II})$ aryl imino phenoxide complexes in our study. The substituents of the ligands seem to have strong electronic effects that influence the redox potential more than the structures. Complex 1 shows a quasi-reversible reduction wave with a half-wave 
Table 3 Electrochemical properties of 1-4 measured by cyclic voltammetry; potentials are given against the ferrocene/ferrocenium redox couple in $\mathrm{mV}$ Estimated error $\pm 3 \%$

\begin{tabular}{lllll}
\hline Catalyst & $E_{\mathrm{red}}\left[\mathrm{Cu}^{\mathrm{II}} \mathrm{L}_{2} / \mathrm{Cu}^{\mathrm{I}} \mathrm{L}_{2}^{-}\right]$ & $E_{1 / 2 \text { red }}\left[\mathrm{Cu}^{\mathrm{II}} \mathrm{L}_{2} / \mathrm{Cu}^{\mathrm{I}} \mathrm{L}_{2}^{-}\right]$ & $E_{\mathrm{ox}}\left[\mathrm{Cu}^{\mathrm{II}} \mathrm{L}_{2} / \mathrm{Cu}^{\mathrm{II}} \mathrm{L}_{2}{ }^{+}\right]$ & $E_{1 / 2 \mathrm{x}}\left[\mathrm{Cu}^{\mathrm{II}} \mathrm{L}_{2} / \mathrm{Cu}^{\mathrm{II}} \mathrm{L}_{2}{ }^{+}\right]$ \\
& $E_{\mathrm{pc}}$ & $E_{1 / 2}$ & $E_{\mathrm{a}}$ & - \\
\hline 1 & - & -1391 & $546 ; 869$ & $503 ; 813$ \\
2 & - & -1377 & - & 1077 \\
3 & -1457 & - & - & - \\
4 & -1778 & - & $606 ; 852$ & $E_{1 / 2}$ \\
\hline
\end{tabular}

potential of $-1391 \mathrm{mV}$ vs. $\mathrm{Fc} / \mathrm{Fc}^{+}\left(I_{\mathrm{pa}} / I_{\mathrm{pc}} \sim 0.9\right.$, Table 3$)$. For complex 2, the oxidative peak of the first reduction potential shows much lower current density, hence the ratio $I_{\mathrm{pa}} / I_{\mathrm{pc}}$ cannot be determined reliably. This effect has been observed earlier with similar compounds and has been ascribed to the decomposition of the complexes due to the instability of the singly reduced species via a process of ligand loss and immediate further reduction from $\mathrm{Cu}(\mathrm{I})$ to $\mathrm{Cu}(0)$.

In a recent publication, the oxidation behavior of similar compounds were ascribed to the formation of a phenoxyl radical [54]. This and further oxidation to a quinine-type oxidation product has been supported by EPR spectroscopy upon chemical oxidation with cerium sulfate for methoxy-substituted imino phenoxide $\mathrm{Cu}(\mathrm{II})$ complexes [52]. Complexes 1, 2, and 4 show similar electrochemical behaviors as described before with different degrees of reversibility of the oxidation reaction $[52,55]$. The oxidation potential of complex 3 is much higher than for the other complexes (Fig. 3). This observation is in line with the assumption that the oxidation is a ligand based process. Contrary to the other ligands, $\mathbf{L 3}$ contains no methyl-substituents but electron-withdrawing bromo-ligands which results in the electron-poorest and hence hardest to oxidize ligand.

Because it is the only compound featuring a reversible reduction, just $\mathbf{1}$ was further investigated by spectroelectrochemistry, which was performed in dichloroethane (DCE) solution containing $0.3 \mathrm{M}$ of $\left[\mathrm{Bu}_{4} \mathrm{~N}\right] \mathrm{PF}_{6}$ as supporting electrolyte using an optically transparent thin layer electrochemical (OTTLE) cell (Fig. 4). As reported above, $\mathrm{Cu}(\mathrm{II})$ is reduced to $\mathrm{Cu}(\mathrm{I})$ under reductive conditions. This results in an change of the nature of lowestenergy transition: $\mathrm{Cu}(\mathrm{I})$ as a closed-shell $\mathrm{d}^{10}$ ion does not show any $\mathrm{d}-\mathrm{d}$ or LMCT transitions but metal-to-ligand transition (MLCT) at comparable energies like the LMCTs for $\mathrm{Cu}(\mathrm{II})$. Hence, the maximum of the $\mathrm{Cu}(\mathrm{II})$ LMCT band at $\sim 400 \mathrm{~nm}$ bleaches, whereas two new bands form at $\sim 353$ and $\sim 456 \mathrm{~nm}$ which are typical for an MLCT of $\mathrm{Cu}(\mathrm{I})$ compounds bearing aromatic ligands $[63,64]$.
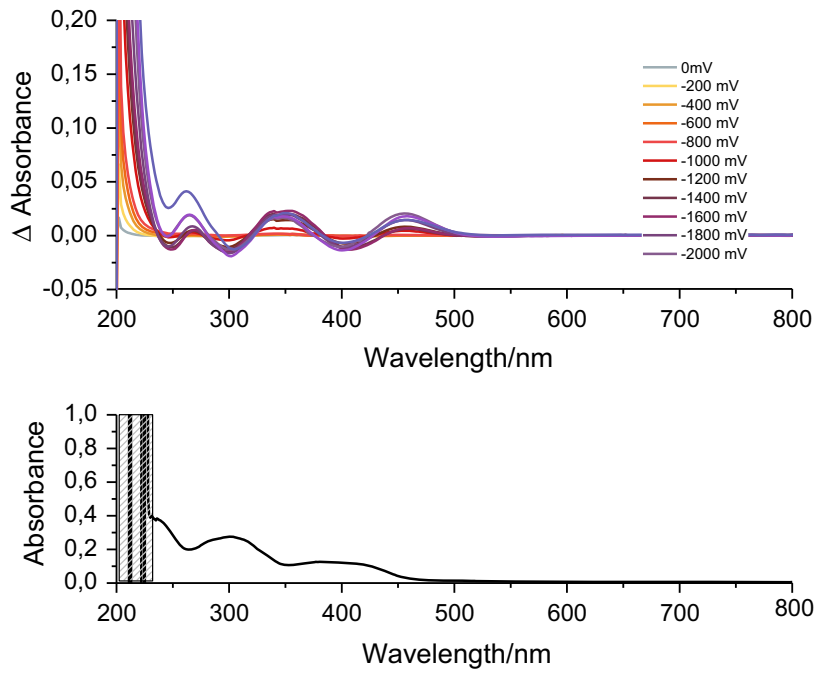

Fig. 4 Spectro-electrochemistry of complex 1 in 0.3 M DCE vs. Ag/ $\mathrm{AgCl}$ (top) and $\mathrm{UV}-\mathrm{Vis}$ spectra of complex 1 in DCM for comparison (bottom)

Scheme 2

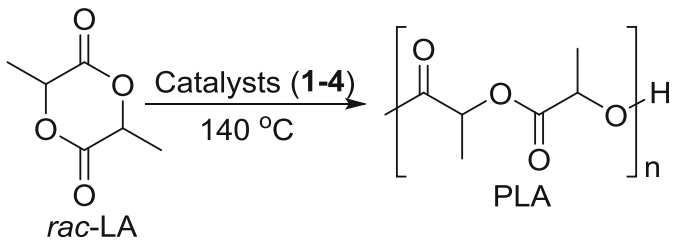

\section{Polymerization studies}

All four complexes were able to initiate the ROP of rac-LA under solvent free conditions generating PLA of moderate molecular weights $(5.30-6.04 \mathrm{~kg} / \mathrm{mol})$ and relatively high polymer dispersities $($ MWDs $=1.71-1.83$, Scheme 2). The polymerizations were carried out at $140{ }^{\circ} \mathrm{C}$ in a ratio of 200:1 (rac-LA:catalyst). The results are summarized in Table 4. The appearances of broader MWDs could be partly explained by transesterification during the polymerization process $[65,66]$, as well as the slow initiation 
Table 4 Polymerization data for rac-LA using 1-4 in 200:1 ratio (rac-LA:catalyst) at $140{ }^{\circ} \mathrm{C}$

\begin{tabular}{lllllc}
\hline Entry & Catalyst & Yield $/ \%$ & $M_{\mathrm{n}}^{\text {obs}} / \mathrm{kg} \mathrm{mol}^{-1 \mathrm{a}}$ & $M_{\mathrm{w}} / M_{\mathrm{n}}$ & 1.78 \\
\hline 1 & $\mathbf{1}$ & 94 & 5.45 & 1.75 & 9.361 \\
2 & $\mathbf{2}$ & 95 & 5.76 & 1.83 & 10.58 \\
3 & $\mathbf{3}$ & 93 & 5.30 & 1.71 & 7.562 \\
4 & $\mathbf{4}$ & 95 & 6.04 & $k_{\mathrm{app}} / \times 10^{-3} \mathrm{~min}^{-1 \mathrm{~b}}$ \\
\hline
\end{tabular}

a Measured by GPC at $60{ }^{\circ} \mathrm{C}$ in DMF relative to polystyrene standards

b As measured from the NMR study

rates in comparison with a fast propagation. Steric and electronic properties of the ligands affect the catalytic efficiency. Complex $\mathbf{4}$ is the only one in this series with a benzyl and not an aryl group bound to the imine nitrogen atom, thus rendering the metal center less sterically hindered. Therefore, $r a c$-LA can approach readily towards the metal center, thereby appeared to be the best catalyst amongst the complexes investigated in this study. As the activities of all catalysts were found to be very low under bulk condition compared to published reports using copper complexes [34-36], further polymerizations in solution were not carried out. The low activity might be due to the fact that the $\mathrm{Cu}$ (II) atoms are coordinatively saturated in the presented complexes. Both accepted polymerization mechanisms, the coordination-insertion and the monomeractivated mechanism, involve the coordination of the carboxylate oxygen atom to the metal atom of the catalyst [67]. Although it is known that $\mathrm{Cu}(\mathrm{II})$ is capable of forming five-coordinate square-pyramidal complexes, the tendency to coordinate an additional donor atom of a substrate molecule seems to be low. Furthermore, the complexes seem to be rather stable. Therefore, the formation of a reactive intermediate with a coordinatively unsaturated metal atom by ligand dissociation is unlikely.

The polymerization kinetics of rac-LA in 200:1 ratio ([rac-LA $\left.]_{0}:[\mathrm{Cat}]_{0}\right)$ using complexes $\mathbf{1 - 4}$ were investigated by monitoring the reaction via ${ }^{1} \mathrm{H}$ NMR spectroscopy. Aliquots of the reaction mixtures were taken out at regular time intervals and the percentage conversion of unreacted monomer to polymer was measured by comparing the peaks at $4.99-5.06 \mathrm{ppm}$ (unreacted monomer) and 5.11-5.25 (polymer). The plot of \%-conversion of rac-LA against time described a sigmoid curve (Fig. 5, left). The plot of $\ln \left([\mathrm{LA}]_{0} /[\mathrm{LA}]_{t}\right)$ vs. time exhibited a good linear relation and indicates that the polymerization proceeds with first order dependence on monomer concentration (Fig. 5, right). The values of the apparent rate constant $\left(k_{\text {app }}\right)$ for $r a c$-LA polymerization catalyzed by 1-4 were evaluated from the slope of these regression lines and are found to be $9.36 \times 10^{-3}, 10.6 \times 10^{-3}, 7.56 \times 10^{-3}$, and $12.8 \times 10^{-3} \mathrm{~min}^{-1}$ for $\mathbf{1 - 4}$, respectively. The polymerization rate is fastest for $\mathbf{4}$ and slowest for $\mathbf{3}$.
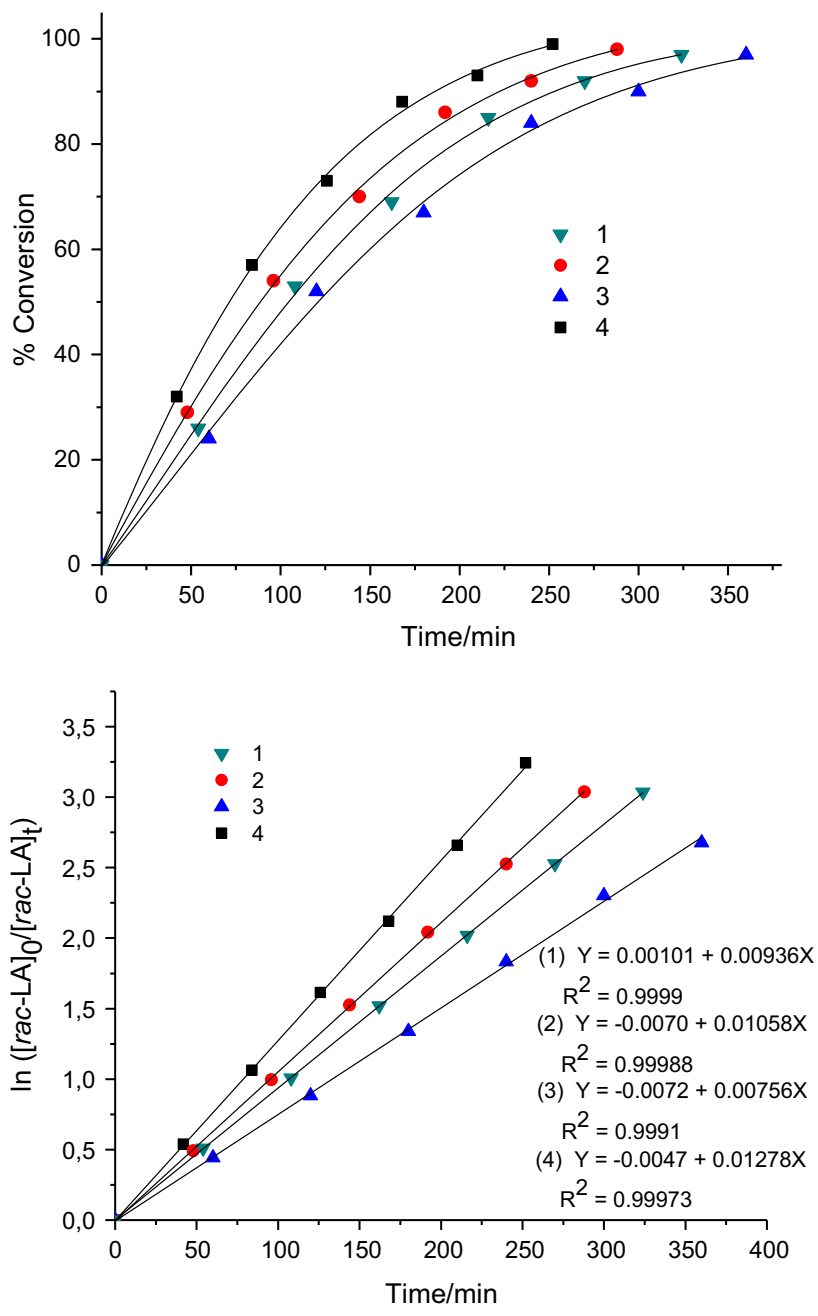

Fig. $5 \mathrm{rac}$-LA conversion vs. time (top) and $\ln \left([\mathrm{LA}]_{0} /[\mathrm{LA}]_{t}\right)$ vs. time plot (bottom) using 1-4: $[\mathrm{rac}-\mathrm{LA}]_{0}:[\mathrm{Cat}]_{0}=200: 1$ at $140{ }^{\circ} \mathrm{C}$

\section{Conclusion}

In summary, we have synthesized four new copper(II) complexes containing imino phenoxide ligands. These compounds were characterized by spectroscopy (IR, UVVis), mass spectrometry, single crystal X-ray crystallography, electrochemistry, and elemental analysis. All 
complexes feature a metal-based reduction from $\mathrm{Cu}$ (II) to $\mathrm{Cu}(\mathrm{I})$ and a ligand-centered oxidation. Only for complex $\mathbf{1}$, the reduction is quasi-reversible, whereas oxidation of all complexes is irreversible. All complexes exhibited low activity towards the ROP of rac-LA in comparison to the literature reported protocols using $\mathrm{Cu}(\mathrm{II})$ complexes. The catalytic activity of $\mathbf{4}$ was found to be highest.

\section{Experimental}

All manipulations were carried out in an atmosphere of dry nitrogen using standard Schlenk techniques. $\mathrm{CDCl}_{3}$ used for NMR spectral measurements was dried over calcium hydride for $48 \mathrm{~h}$, distilled and stored in a glove box. IR spectroscopy was performed on a Shimadzu IRAffinity-1 FTIR spectrophotometer that was equipped with a Specac Golden Gate ${ }^{\mathrm{TM}}$ single-reflection diamond ATR accessory. Mass spectra were collected on a Finnigan LCQ DecaXP ${ }^{\text {Plus }}$ Ion Trap Mass spectrometer with an ESI ion source. Elemental analyses were carried out at the Institute for Chemical Technology of Organic Materials at JKU. For photophysical characterization, spectroscopic grade solvents were used throughout all measurements. Absorption spectra were recorded with a Varian Cary 300 or 50 spectrophotometer. All $\varepsilon$ values are given in $\mathrm{dm}^{3} \mathrm{~mol}^{-1} \mathrm{~cm}^{-1}$. Cyclic voltammetry (CV) experiments were carried out under inert conditions in a glovebox using an Eco Autolab potentiostat with a self-made three-electrode cell consisting of a BASi platinum working electrode, a platinum wire as a counter electrode and a silver/silver chloride quasi-reference electrode. The $\mathrm{Pt}$ working electrode was polished with $0.1 \mathrm{~mm}$ alumina powder and washed with dilute $\mathrm{HNO}_{3}$ and double distilled water. The complexes were dissolved in dichloromethane with $0.1 \mathrm{M}$ tetrabutylammonium hexafluorophosphate $\left(\mathrm{TBAPF}_{6}\right)$ as the supporting electrolyte. Scanning rates of 50-200 mV/s were applied. Ferrocene was employed as internal standard for potential referencing, and the potentials were subsequently referenced vs. SCE accordingly [68]. Cyclic voltammograms of all complexes were recorded in the potential range of +1.6 to $-1.6 \mathrm{~V}$. Spectro-electrochemistry was performed in a thin layer OTTLE cell [69] with a platinum working electrode, a platinum wire as a counter electrode, and a silver reference electrode. The corresponding UV-Vis absorption spectra were collected with a Jasco V670 Spectrometer.

\section{Materials}

Dichloromethane was dried and distilled over $\mathrm{K}_{2} \mathrm{CO}_{3}$, and methanol was dried and distilled over $\mathrm{Na} . \mathrm{Cu}(\mathrm{OAc})_{2} \cdot 2 \mathrm{H}_{2} \mathrm{O}$ was purchased from Sigma-Aldrich and used without further purification. rac-LA was purchased from Sigma-
Aldrich and sublimed under a nitrogen atmosphere repeatedly for further purification and stored in a glove box. All other solvents and reagents were commercially available and used as received. Ligands L1-L4 were prepared according to literature reported procedures $[56,57]$.

\section{Synthesis of complexes 1-4}

General procedure for the synthesis of 1-4: a methanolic solution $\left(20 \mathrm{~cm}^{3}\right)$ of the Schiff base $(1 \mathrm{mmol})$ and copper acetate $(0.5 \mathrm{mmol})$ in $10 \mathrm{~cm}^{3}$ methanol were mixed thoroughly and the mixture was heated under reflux for $2 \mathrm{~h}$ and then cooled to room temperature. After filtration the resulting solution was evaporated to dryness and the residue was recrystallized from dichloromethane.

Bis[2-[(4-methoxyphenyl)iminomethyl]-4,6-dimethylphenolato- $\kappa^{2} N, O^{1}$ copper(II) $\left(1, \mathrm{C}_{32} \mathrm{H}_{32} \mathrm{CuN}_{2} \mathrm{O}_{4}\right)$

Yield $0.08 \mathrm{~g}(81 \%)$; ESI-MS: $\mathrm{m} / \mathrm{z}$ calculated for $\mathrm{C}_{32} \mathrm{H}_{32}$ $\mathrm{CuN}_{2} \mathrm{O}_{4} \mathrm{Na}\left([\mathrm{M}+\mathrm{Na}]^{+}\right)$594.17, found 594.33; IR (ATR): $\bar{v}=1619(-\mathrm{CH}=\mathrm{N}), 1506(\mathrm{Ar}-\mathrm{OMe}) \mathrm{cm}^{-1}$.

Bis[2-[(4-methoxyphenyl)iminomethyl]-4-methyl-6-(tertbutyl)phenolato- $\left.\kappa^{2} N, O^{1}\right]$ copper(II) $\left(2, \mathrm{C}_{38} \mathrm{H}_{44} \mathrm{CuN}_{2} \mathrm{O}_{4}\right)$ Yield $0.07 \mathrm{~g}(82 \%)$; ESI-MS: $\mathrm{m} / \mathrm{z}$ calculated for $\mathrm{C}_{38} \mathrm{H}_{44}$ $\mathrm{CuN}_{2} \mathrm{O}_{4} \mathrm{Na}\left([\mathrm{M}+\mathrm{Na}]^{+}\right)$678.30, found 678.40; IR (ATR): $\bar{v}=1616(-\mathrm{CH}=\mathrm{N}), 1506(\mathrm{Ar}-\mathrm{OMe}) \mathrm{cm}^{-1}$.

Bis[2,4-dibromo-6-[(2,6-diisopropylphenyl)iminomethyl]phenolato- $\kappa^{2} N, O^{1}$ ]copper(II)

$\left(3, \mathrm{C}_{38} \mathrm{H}_{40} \mathrm{Br}_{4} \mathrm{CuN}_{2} \mathrm{O}_{2}\right)$

Yield $0.07 \mathrm{~g}(80 \%)$; ESI-MS: $\mathrm{m} / \mathrm{z}$ calculated for $\mathrm{C}_{38} \mathrm{H}_{41}$ $\mathrm{Br}_{4} \mathrm{CuN}_{2} \mathrm{O}_{2}\left([\mathrm{M}+\mathrm{H}]^{+}\right)$935.93, found 935.13; IR (ATR): $\bar{v}=1606(-\mathrm{CH}=\mathrm{N}) \mathrm{cm}^{-1}$.

Bis[2-[(4-methoxybenzyl)iminomethyl]-4-methyl-6-(tertbutyl)phenolato- $\left.\kappa^{2} N, O^{1}\right]$ copper(II) $\left(4, \mathrm{C}_{40} \mathrm{H}_{48} \mathrm{CuN}_{2} \mathrm{O}_{4}\right)$ Yield $0.06 \mathrm{~g}(83 \%)$; ESI-MS: $\mathrm{m} / \mathrm{z}$ calculated for $\mathrm{C}_{40} \mathrm{H}_{48}$ $\mathrm{CuN}_{2} \mathrm{O}_{4} \mathrm{Na}\left([\mathrm{M}+\mathrm{Na}]^{+}\right)$706.29, found 706.33; IR (ATR): $\bar{v}=1620(-\mathrm{CH}=\mathrm{N}), 1513(\mathrm{Ar}-\mathrm{OMe}) \mathrm{cm}^{-1}$.

\section{X-ray structure determination of complexes 1-4}

Suitable single crystals for X-ray diffraction were obtained for all four compounds under ambient conditions from concentrated dichloromethane solution of the respective compounds over a period of 7 days. Diffraction data were collected on a Bruker Smart X2S diffractometer operating with Mo $\mathrm{K} \alpha$ radiation $(\lambda=0.71073 \AA)$. The structures were solved by direct methods (SHELXS-97) [70, 71] and refined by full-matrix least squares on $F^{2}$ (SHELXL-97) $[72,73]$. The $\mathrm{H}$ atoms were calculated geometrically, and a riding model was applied in the refinement process. These data were deposited with CCDC with the following numbers: CCDC 1448157-1448160 and can be obtained free of 
Table 5 Crystal data for the structures of 1-3

\begin{tabular}{|c|c|c|c|}
\hline Compound & 1 & 2 & 3 \\
\hline Empirical formula & $\mathrm{C}_{32} \mathrm{H}_{32} \mathrm{CuN}_{2} \mathrm{O}_{4}$ & $\mathrm{C}_{38} \mathrm{H}_{44} \mathrm{CuN}_{2} \mathrm{O}_{4}$ & $\mathrm{C}_{38} \mathrm{H}_{40} \mathrm{Br}_{4} \mathrm{CuN}_{2} \mathrm{O}_{2}$ \\
\hline Formula weight & 572.14 & 656.29 & 939.90 \\
\hline Crystal system & Orthorhombic & Monoclinic & Triclinic \\
\hline Space group & $F d d 2$ & $C 2 / c$ & $P \overline{1}$ \\
\hline Temp/K & 300 & 300 & 300 \\
\hline$a / \AA$ & $34.075(2)$ & $14.640(2)$ & $9.3893(8)$ \\
\hline$b / \AA$ & $12.3830(9)$ & $29.944(3)$ & $9.4713(10)$ \\
\hline$c / \AA$ & $13.3134(10)$ & $17.637(2)$ & $12.4322(13)$ \\
\hline$\alpha /^{\circ}$ & 90 & 90 & $112.224(3)$ \\
\hline$\beta /^{\circ}$ & 90 & $114.285(4)$ & $95.405(3)$ \\
\hline$\gamma /{ }^{\circ}$ & 90 & 90 & $99.214(3)$ \\
\hline$V / \AA^{3}$ & $5617.6(7)$ & $7047.5(16)$ & $995.65(17)$ \\
\hline$Z$ & 8 & 8 & 1 \\
\hline$D_{\text {calc }} / \mathrm{g} \mathrm{cm}^{-3}$ & 1.353 & 1.237 & 1.568 \\
\hline Reflns collected & 17380 & 63378 & 18297 \\
\hline Indep. reflns & 2016 & 8153 & 3517 \\
\hline Obs. reflns $[I>2 \sigma(I)]$ & 1931 & 3619 & 2801 \\
\hline Param. refin./restr. & $181 / 1$ & $417 / 0$ & $218 / 0$ \\
\hline Absorption correction & Multi-scan & Multi-scan & Multi-scan \\
\hline$R_{1}$ & 0.059 & 0.060 & 0.0459 \\
\hline$w R_{2}$ & 0.128 & 0.17 & 0.128 \\
\hline $\mathrm{CCDC}$ & 1448157 & 1448158 & 1448159 \\
\hline
\end{tabular}

charge from the Cambridge Crystallographic Data Centre at https://summary.ccdc.cam.ac.uk/structure-summaryform. Crystal data are given in Table 5 and S1.

\section{General procedure for the bulk polymerization of $r a c$-LA}

The polymerizations were performed under solvent free conditions in 200:1 ratio of rac-LA and the complexes with $173 \mu \mathrm{mol}$ of $\mathbf{1 - 4}$ and $5.00 \mathrm{~g}$ of $\mathrm{rac}$-LA $(34.7 \mathrm{mmol})$ under a nitrogen atmosphere in a $50 \mathrm{~cm}^{3}$ flask. Under stirring, the flask was heated to $140{ }^{\circ} \mathrm{C}$. Once the monomer melted fully, a rise in viscosity due to the polymerization reaction was observed and finally the stirring ceased. Then the reaction mixture was dissolved into a minimum quantity of $\mathrm{CH}_{2} \mathrm{Cl}_{2}$ and poured into cold methanol. The polymer precipitated immediately and was collected by filtration. The filtered product was dried in vacuum until a constant weight was achieved. Cold methanol was used for the quenching of the polymerization reaction. The formed polymer was filtered and dried in vacuum.

\section{Kinetics of rac-LA polymerization}

To determine the kinetics of the polymerization of $r a c$-LA, a polymerization reaction in small scale at a temperature of
$140{ }^{\circ} \mathrm{C}$ under nitrogen atmosphere were carried out. At 200:1 ratio the polymerizations were performed by charging $11.6 \mu \mathrm{mol}$ of $\mathbf{1 - 4}$ (7 mg of $\mathbf{1}, 8 \mathrm{mg}$ of $\mathbf{2}, 11 \mathrm{mg}$ of $\mathbf{3}$, and $8 \mathrm{mg}$ of 4$)$ and $1.00 \mathrm{~g}$ of rac-LA (6.94 mmol). Aliquots were taken out at regular time intervals from the glass reactor under argon atmosphere and ${ }^{1} \mathrm{H}$ NMR spectra were recorded to determine the $\%$ conversion of monomer into the corresponding polymer by comparing the methine proton of the unreacted monomer and polymer. Apparent rate constant $\left(k_{\mathrm{app}}\right)$ were obtained from the slopes of the best fit lines from a plot of $\ln \left([\mathrm{rac}-\mathrm{LA}]_{0} /[\mathrm{rac}-\mathrm{LA}]_{t}\right)$ vs. time.

\section{Characterization of polymers}

Molecular weights $\left(M_{\mathrm{n}}\right)$ and molecular weight distributions (MWDs) of the polymer samples produced by the ROP of rac-LA were determined using gel permeation chromatography (GPC). GPC was performed on a Viscothek GPCmax instrument using a PFG column from PSS (Mainz, Germany, $300 \mathrm{~mm} \times 8 \mathrm{~mm}, 5 \mu \mathrm{m}$ particle size). The samples were eluted with DMF containing $5 \mathrm{mM} \mathrm{LiBr}$ as the mobile phase at a flow rate of $0.75 \mathrm{~cm}^{3} \mathrm{~min}^{-1}$ at $60{ }^{\circ} \mathrm{C}$. The molecular weights were calculated relative to polystyrene standards from PSS using a conventional calibration of the refractive index detector. The samples were 
filtered through a nylon microfilter $(0.2 \mu \mathrm{m})$ prior to the measurement.

Acknowledgments Open access funding provided by Johannes Kepler University Linz. M.M. thanks for a scholarship within the framework of Erasmus Mundus Action 2 doctoral exchange program of the European Commission. We thank the JKU and Prof. Knör (JKU) for his generous support of the experimental work. The NMR spectrometers were acquired in collaboration with the University of South Bohemia (CZ) with financial support from the European Union through the EFRE INTERREG IV ETC-AT-CZ program (project M00146, “RERI-uasb”).

Open Access This article is distributed under the terms of the Creative Commons Attribution 4.0 International License (http:// creativecommons.org/licenses/by/4.0/), which permits unrestricted use, distribution, and reproduction in any medium, provided you give appropriate credit to the original author(s) and the source, provide a link to the Creative Commons license, and indicate if changes were made.

\section{References}

1. Cozzi PG (2004) Chem Soc Rev 33:410

2. Hernández-Molina R, Mederos (2003) Compr Coord Chem II $2: 411$

3. Saha TK, Mandal M, Chakraborty D, Ramkumar V (2013) New J Chem 37:949

4. Ghosh S, Chakraborty D, Varghese B (2015) Eur Polym J 62:51

5. Roymuhury SK, Chakraborty D, Ramkumar V (2015) Dalton Trans 44:10352

6. Chakraborty D, Mandal M (2016) A process for the preparation of biopolymers. Indian Pat IN2014KO01271 A, 10 Jun 2016, (2016) Chem Abstr 967690

7. Ghosh S, Gowda RR, Jagana R, Chakraborty D (2015) Dalton Trans 44:10410

8. Saha TK, Mandal M, Thunga M, Ramkumar V, Chakraborty D (2013) Dalton Trans 42:10304

9. Ragauskas AJ, Williams CK, Davison BH, Tschaplinski T (2006) Science 311:484

10. Williams CK, Hillmyer MA (2008) Polym Rev 48:1

11. Dove AP (2008) Chem Commun 48:6446

12. Nicolas J, Mura S, Brambilla D, Mackiewicz N, Couvreur P (2013) Chem Soc Rev 42:1147

13. Dechy-Cabaret O, Martin-Vaca B, Bourissou D (2004) Chem Rev 104:6147

14. Jerome C, Lecomte P (2008) Adv Drug Deliv Rev 60:1056

15. Tschan MJ-L, Brulé E, Haquette P, Thomas CM (2012) Polym Chem 3:836

16. Wu J, Yu T-L, Chen C-T, Lin C-C (2006) Coord Chem Rev 250:602

17. Drumright RE, Gruber PR, Henton DE (2000) Adv Mater $12: 1841$

18. Mandal M, Chakraborty D (2016) J Polym Sci Part A Polym Chem 54:809

19. Mandal M, Chakraborty D, Ramkumar V (2015) RSC Adv 5:28536

20. Tsai C-Y, Du H-C, Chang J-C, Huang B-H, Ko B-T, Lin C-C (2014) RSC Adv 4:14527

21. Wang L, Poirier V, Ghiotto F, Bochmann M, Cannon RD, Carpentier J-F, Sarazin Y (2014) Macromolecules 47:2574
22. Aluthge DC, Patrick BO, Mehrkhodavandi P (2013) Chem Commun 49:4295

23. Sauer A, Kapelski A, Fliedel C, Dagorne S, Kol M, Okuda J (2013) Dalton Trans 42:9007

24. Dagorne S, Normand M, Kirillov E, Carpentier J-F (2013) Coord Chem Rev 257:1869

25. Nie K, Gu W, Yao Y, Zhang Y, Shen Q (2013) Organometallics 32:2608

26. Gilding DK, Read AM (1979) Polymer 20:1459

27. John A, Katiyar V, Pang K, Shaikh MM, Nanavati H, Ghosh P (2007) Polyhedron 26:4033

28. Chen L-L, Ding L-Q, Zeng C, Long Y, Lu X-Q, Song J-R, Fan D-D, Jin W-J (2011) Appl Organomet Chem 25:310

29. Gowda RR, Chakraborty D (2011) J Mol Catal A Chem 349:86

30. Whitehorne TJJ, Schaper F (2012) Chem Commun 48:10334

31. Li C-Y, Hsu S-J, Lin C-L, Tsai C-Y, Wang J-H, Ko B-T, Linand C-H, Huang H-Y (2013) J Polym Sci Part A Polym Chem $51: 3840$

32. Appavoo D, Omondi B, Guzei IA, Wyk JLV, Zinyemba O, Darkwa J (2014) Polyhedron 69:55

33. Routaray A, Nath N, Maharana T, Sutar AK (2015) J Macromol Sci Pure Appl Chem 52:444

34. Whitehorne TJJ, Schaper F (2013) Inorg Chem 52:13612

35. Kwon KS, Cho J, Nayab S, Jeong JH (2015) Inorg Chem Commun 55:36

36. Fortun S, Daneshmand P, Schaper F (2015) Angew Chem Int Ed 54:13669

37. Wang X, Zhao K-Q, Elsegood MRJ, Prior TJ, Liu X, Wu L, Sanz S, Brechine EK, Redshaw C (2015) RSC Adv 5:57414

38. Swierczynski D, Luboradzki R, Dolgonos G, Lipkowski J, Schneider H-J (2005) Eur J Org Chem 6:1172

39. Nagels N, Hauchecorne D, Herrebout WA (2013) Molecules $18: 6829$

40. Sundaravel K, Suresh E, Palaniandavar M (2009) Inorg Chim Acta 362:199

41. Garnovskii AD, Nivorozhkin AL, Minkin VI (1993) Coord Chem Rev 126:1

42. Carlini C, Giaiacopi S, Marchetti F, Pinzino C, Galletti AMR, Sbrana G (2006) Organometallics 25:3659

43. Safaei E, Kabir MM, Wojtczak A, Jagličić Z, Kozakiewicz A, Lee Y-I (2011) Inorg Chim Acta 366:275

44. Lacroix PG, Averseng F, Malfant I, Nakatani K (2004) Inorg Chim Acta 357:3825

45. Upadhyay A, Vaidya S, Venkatasai VS, Jayapal P, Srivastava AK, Shanmugam M, Shanmugam M (2013) Polyhedron 66:87

46. Costamagna J, Caruso F, Vargas J, Manriquez V (1998) Inorg Chim Acta 267:151

47. Aguilar-Martínez M, Saloma-Aguilar R, Macías-Ruvalcaba N, Cetina-Rosado R, Navarrete-Vázquez A, Gómez-Vidales V, Zentella-Dehesa A, Toscano RA, Hernández-Ortega S, Fernández-G JM (2001) J Chem Soc Dalton Trans: 2346

48. Şenol C, Hayvali Z, Dal H, Hökelek T (2011) J Mol Struct 997:53

49. Zhang X-L (2010) Z Kristallogr NCS 225:711

50. Kasumov VT, Uçar İ, Bulutand A, Köksal F (2007) Z Naturforsch $62 \mathrm{~b}: 1133$

51. Eren T, Kose M, Kurtoglu N, Ceyhan G, McKee V, Kurtoglu M (2015) Inorg Chim Acta 430:268

52. Patterson GS, Holm RH (1975) Bioinorg Chem 4:257

53. Kasumov VT, Köksal F (2002) Spectrochim Acta Part A 58:2199

54. Kasumov VT, Köksal F (2012) Spectrochim Acta Part A 98:207

55. Raja KK, Easwaramoorthy D, Rani SK, Rajesh J, Jorapur Y, Thambidurai S, Athappan PR, Rajagopal G (2009) J Mol Catal A Chem 303:52

56. Kasumov VT, Köksal F, Sezer A (2005) Polyhedron 24:1203 
57. Bhunora S, Mugo J, Bhaw-Luximon A, Mapolie S, Wyk JV, Darkwa J, Nordlander E (2011) Appl Organomet Chem 25:133

58. Toda F, Tanaka K, Miyahara I, Akutsu S, Hirotsu K (1994) J Chem Soc Chem Commun 15:1795

59. Nishio M (2004) CrystEngComm 6:130

60. Nishio M (2005) Tetrahedron 61:6923

61. Percino MJ, Cerón M, Soriano-Moro G, Castro ME, Chapela VM, Bonilla J, Reyes-Reyes M, López-Sandoval R (2014) CrystEngComm 16:8591

62. Kasumov VT, Medjidov AA, Yayli N, Zeren Y (2004) Spectrochim Acta Part A 60:3037

63. Kern T, Monkowius U, Zabel M, Knör G (2011) Inorg Chim Acta 374:632

64. Monkowius U, Svartsov YN, Fischer T, Zabel M, Yersin H (2007) Inorg Chem Commun 10:1473
65. Dubois P, Jacobs C, Jérôme R, Teyssié P (1991) Macromolecules 24:2266

66. Chamberlain BM, Jazdzewski BA, Pink M, Hillmyer MA, Tolman WB (2000) Macromolecules 33:3970

67. Silvernail CM, Yao LJ, Hill LMR, Hillmyer MA, Tolman WB (2007) Inorg Chem 46:6565

68. Pavlishchuk VV, Addison AW (2000) Inorg Chim Acta 298:97

69. Krejčik M, Daněk M, Hartl F (1991) J Electroanal Chem Interfac Electrochem 317:179

70. Sheldrick GM (1997) SHELXS-97, program for the solution of crystal structures, Göttingen, Germany

71. Sheldrick GM (1990) Acta Crystallogr A 46:467

72. Sheldrick GM (1997) SHELXL-97, program for crystal structure refinement, Göttingen, Germany

73. Sheldrick GM (2008) Acta Crystallogr A 64:112 